www.jmscr.igmpublication.org

Impact Factor 5.84

Index Copernicus Value: 83.27

ISSN (e)-2347-176x ISSN (p) 2455-0450

crossref DOI: _https://dx.doi.org/10.18535/jmscr/v5i4.163

Journal Of Medical Science And Clinical Research

\title{
Comparative Study on the Effectiveness of Granisetron and Metoclopramide for Reducing Propofol Injection Pain
}

\author{
Authors \\ Dr Aravind Johnson, Dr Harikrishnan S, Dr Radhika Devi B
}

Department of Anaesthesiology, Government Medical College Hospital Thiruvananthapuram, Kerala

\begin{abstract}
Background: Propofol is one of the widely used intravenousanaesthetics, although pain on injection still remains a considerable concern for the anaesthesiologists. The aim of my randomized double blinded study was to compare the effectiveness of Granisetron and Metoclopramide in reducing Propofol injection pain. Both these drugs are used as anti emetic drugs. This study also compares the effectiveness of Granisetron and Metoclopramide in reducing post operative nausea and vomiting.

Methods: 760 patients, aged 21-50 years ,American society of Anaesthesiologists grading (ASA) 1-2, scheduled for various surgeries under general anaesthesia were randomly assigned to one of two groups (380 in each group). One group (Group A) received $2 \mathrm{ml}$ Granisetron ( $1 \mathrm{mg} / \mathrm{ml})$ while the other group (Group B) received $2 \mathrm{ml}$ Metoclopramide $(5 \mathrm{mg} / \mathrm{ml})$ and were accompanied by manual venous occlusion for one minute. Then $2 \mathrm{ml}$ Propofol was injected through the same cannula. Patients were asked by a blinded anaesthesiologist to score pain on injection of Propofol with a four point scale (VRS-Verbal Rating Scale): $0=$ no pain, $1=$ mild pain, 2=moderate pain, 3=severe pain. The Post operative nausea/vomiting was assessed by Visual Analog Scale $(0=$ no symptoms, $10=$ worst symptoms)

Results: 65 patients $(17.1 \%)$ complained of pain in group pretreatedwith Granisetron that is 31 patients (8.1\%) with mild pain (VRS 1), 20 patients (5.3\%) with moderate pain (VRS 2), 14 patients (3.7\%) with severe pain (VRS 3). 151 patients (39.7\%) complained of pain in group pretreated with Metoclopramide that is is 76 patients (20\%) with mild Pain (VRS 1), 57 patients (15\%) with moderate pain (VRS 2), 18 patients (4.7\%) with severe pain (VRS 3). The presence and severity of pain was less in the Granisetron group compared with Metoclopramide group $(P<0.05)$.

In Granisetron group, 41 patients (10.8\%) complained of post operative nausea /vomiting that is $38(10 \%)$ had VAS score 1, 2 (0.5\%) had VAS score 2, 1 (0.3\%) had VAS score 1. In Metoclopramide group, 112 patients (29.5\%) complained of post operative nausea /vomiting that is 76 (20\%) had VAS score 1, 19 (5\%) had VAS score 2, 17 (4.5\%) had VAS score 3. The presence and severity of post operative nausea and vomiting was less in the Granisetron group compared with Metoclopramide group $(P<0.05)$.

Conclusion: Intravenous Granisetron at a dose of $2 \mathrm{mg}$ was moreeffective than intravenous Metoclopramide at a dose of $10 \mathrm{mg}$ along with manual occlusion for one minute in reducing Propofol injection pain when given before propofol injection. Also, Granisetron was more effective than Metoclopramide in reducing post operative nausea and vomiting.
\end{abstract}




\section{Introduction}

Anaesthesia can be defined as the provision of insensibility to pain with adequate management of vital functions during various therapeutic and diagnostic procedures. With the decrease in adverse events after surgery, patient satisfaction with perioperative care is assuming more importance.

Ever since its introduction in the clinical scenario in 1977, propofol has attained unmatched popularity as an agent for intravenous (i.v.) induction. It is also used for short duration surgery, sedation and ambulatory surgery. But very often, it has the disadvantage of causing pain or discomfort on injection, especially when given in small veins on the dorsum of hand. This pain may be distressing to the patients and can reduce the acceptability of an otherwise useful agent. ${ }^{[1]}$ Among 33 low morbidity clinical outcomes, considering clinical importance and frequency, pain during injection of propofol was ranked as the seventh most important problem of current clinical anesthesiology. ${ }^{[2]}$ Incidence of pain with intravenous propofol varies between $28 \%$ and $90 \%$ in adults and $28 \%$ and $85 \%$ in children . ${ }^{[3][4]}$ Several techniques were proposed over the years to reduce the incidence and severity of such pain. However, all had variable results. ${ }^{[4-13]}$

Many factors like site of injection, size of vein, speed of injection, buffering effect of blood, temperature of propofol and concomitant use of drugs such as local anaesthetics, opiates, etc., appear to affect the incidence of pain ${ }^{[14-16]}$. A number of both pharmacological (e.g., pretreatment with lignocaine, ondansetron, ketorolac, nafamostat, ketamine or topical nitroglycerine application with propofol, diluting propofol with $5 \%$ dextrose or $10 \%$ intralipid and using mediumand small-chain triglycerides) and nonpharmacological methods have been used with variable results and the research for the ideal agent to decrease pain on propofol injection is still going on. Nausea and vomiting occurs in 20-30\% of patients in the postoperative period complaints reported ${ }^{[24][25][26][27][28][29][30][30]}$
White ${ }^{[31]}$, postoperative nausea and vomiting $(P O N V)$ became the more commonly used clinical term; and in 1999, PONV became a medical subject heading in the National Library of Medicine. The term PONV will be used throughout this chapter to reflect its current widespread usage to describe the composite postoperative symptoms of nausea and/or vomiting and/or retching. However, the description of these symptoms as "postoperative" should not be construed to suggest that surgery is their most important direct cause, although this is a widely held belief. Several large prospective cohort studies now suggest that the varying incidence of PONV observed after different types of surgeries are largely a reflection of important patient-specific and anaesthesia-related risk factors rather than surgery itself. PONV can be such an unpleasant experience that patients often rate it worse than postoperative pain ${ }^{[32]}$. Prevention of PONV in high-risk patients significantly improves postoperative ratings of well-being and satisfaction. $^{[33]}$

While the experience of PONV is generally selflimited, postoperative vomiting/retching (PONV) can lead to rare but serious medical complications such as aspiration of gastric contents, suture dehiscence, oesophageal rupture, subcutaneous emphysema, or pneumothorax (the actual incidence due to PONV has not been quantified). [34][35] PONV may delay patient discharge from post anaesthesia care units (PACUs) and can be the leading cause of unexpected hospital admission after ambulatory anaesthesia. ${ }^{[36]}$

It has been demonstrated that ondansetron, a specific 5-hydroxytrptamine (5HT3) receptor antagonist, provided numbness when injected under the skin. ${ }^{[37]}$ It has been further demonstrated that ondansetron successfully relieved pain following propofol injection without any adverse effects in a significant number of patients.

Granisetron is a serotonin 5HT3 receptor antagonist and demonstrates superior efficacy and longer duration to ondansetron. 
Metoclopramide shares structural and physicochemical properties with lignocaine and is a weak local anaesthetic ${ }^{[38][39]}$. It has been shown to be as effective as lignocaine in reducing propofol injection pain ${ }^{[40]}$.

This study compares the effectiveness of Granisetron and Metoclopramide in reducing Propofol injection pain and also compares the effectiveness of Granisetron and Metoclopramide in reducing post operative nausea and vomiting.

\section{Aims and Objectives}

The aim of this study is to compare the effectiveness of Granisetron and Metoclopramide for reducing propofol injection pain.

\section{Objectives}

\section{Primary objective}

- To compare the effectiveness of Granisetron and Metoclopramide for reducing propofol injection pain.

\section{Secondary objective}

- To compare the effectiveness of Granisetron and Metoclopramide for reducing post operative nausea and vomiting.

\section{Materials and Methods}

Study Design: A double blind randomised controlled study

Study Period: Twelve months

Setting of the Study: Department of Anaesthesiology, Government medical college, Thiruvananthapuram.

Study Population: Includes 760 patients coming for elective surgery under general anaesthesia during the study period satisfying the following inclusion and exclusion criteria.

\section{Inclusion Criteria}

1. ASA(PS) $1 \& 2$ patients

2. 2Adults in age group 21-50years

\section{Exclusion Criteria}

1. Patient refusal

2. Neurological deficit

3. History of allergy to propofol and study drugs.
4. History of taking any analgesic before surgery

5. Emergency surgery

\section{Sample Size}

Reference 1: Pre-treatment with intravenous Granisetron to alleviate painon propofol injection: A double -blind randomized, controlled trial (Ahmed etal IJA Mar-Apr 2012-15\% complained of pain with

Granisetron $^{[71]}$ ).

Reference 2: Pain on injection of propofol: The mitigating influence ofMetoclopramide using different techniques (W J Liaw etal Acta anaesthesiologica Scandinavica 1999-23\% complained of pain with Metoclopramide $\left.{ }^{[11]}\right)$.

$\mathrm{N}=\frac{2 *\left(\mathrm{Z}_{(1-\alpha / 2)}+\mathrm{Z}_{(1-\beta)}\right)^{2} * \mathrm{P} * \mathrm{Q}}{\mathrm{D}^{\overline{2}}}$

$\mathrm{P}=(23+15) / 2=19$;

Substituting $\mathrm{P}=19 ; \mathrm{Q}(100-\mathrm{P})=81 ; \mathrm{D}=8(23-15)$;

$\mathrm{Z}_{(1-\alpha / 2)}=1.96 ; \quad \mathrm{Z}_{(1-\beta)}=0.842$

$\mathrm{N}=380$ in each group.

The total sample size is 760 with 380 in each group .

\section{Methodology}

760 Study subjects are selected from patients posted for elective surgery under general anaesthesia after applying inclusion and exclusion criteria. Selected patients are asked about their willingness to participate in the study after explaining the details of the study to them.

All patients undergo a detailed preoperative evaluation prior to surgery, including

Detailed history Age and weight

General and systemic examination Airway assessment

Type of surgery

Investigations:

Haemoglobin,

Total and differential count

Renal function test, Serum electrolytes

Platelet count, ECG, Chest X-ray.

Screening markers- for HIV, HBsAg, HCV, VDR.

All patients will be fasted for $8 \mathrm{hrs}$ and will receive ranitidine $150 \mathrm{mg}$ in the evening and on 
morning of surgery. Patient will be randomized into two groups using a computer generated random number table into

Group A - those receiving intravenous Granisetron $2 \mathrm{ml}(1 \mathrm{mg} / \mathrm{ml})$. Group B - those receiving intravenous Metoclopramide $2 \mathrm{ml}(5 \mathrm{mg} / \mathrm{ml})$.

All drugs were prepared by an anaesthesiologist (who is not blinded) not included during induction of anaesthesia. The patient as well as anaesthesiologist who induce the patient (who gives the study drugs) will be unaware of nature of test drug. No patient was given any premedication (except ranitidine) before the pretreatment injection.

Standard monitors ECG, pulse oximeter, noninvasive blood pressure (NIBP), and end tidal carbon dioxide were atached and baseline vital parameters of patient were recorded before injecting propofol and at 1 and 3 min after. The intravenous (i.v) access was established with $18 \mathrm{G}$ cannula without any local infiltration in suitable vein on dorsum of non dominant hand and intravenous fluid $(0.9 \%$ normal saline $)$ was infused.

Each patient received $2 \mathrm{ml}$ of pretreatment solution for a period of $5 \mathrm{~s}$ while the venous drainage was occluded manually at mid forearm for 1 minute to increase the local concentration of drug. Then the occlusion was released and anaesthesia was induced with propofol $2.5 \mathrm{mg} / \mathrm{kg}$. The initial $2 \mathrm{ml}$ bolus was given over $4 \mathrm{~s} ; 15$ seconds later, the patient was asked to rate immediately any sensation of pain during injection of propofol.

The grading of pain was similar to the method used in previous studies and will be explained to patient at the pre anaesthetic visit as well as before giving propofol injection. Thereafter, induction of anaesthesia will be achieved with propofol and for analgesia, fentanyl $2 \mathrm{ug} / \mathrm{kg}$ will be given to all patients. The patients will be intubated with appropriate size endotracheal tube after giving vecuronium. Anaesthesia will be maintained with isoflurane and nitrous oxide-oxygen (66-33\%).

\section{Outcome}

The pain during injection of propofol will be evaluated using a Verbal

Rating Scale (VRS):

0 - none (negative response to questioning)

1 - mild pain (pain reported only in response to questioning without any behavioural signs)

2 - moderate pain (pain reported in response to questioning and accompanied by behavioural signs or pain reported without questioning)

3 -severe pain (strong vocal response or response accompanied by facial grimacing, arm withdrawal or tears)

The post operative nausea and vomiting (in $24 \mathrm{hr}$ period) will be assessed using Visual Analog Scale (VAS). The patient is asked to rate severity of nausea and vomiting between ' $0-10$ ' with ' 0 ' corresponding to no symptoms and ' 10 ' corresponding to worst possible symptoms.

\section{Observations and Results Statistical Interpretation}

Chi. Square test, Mann Whitney U test were used for analysis.

A ' $P$ ' value of less than 0.05 was considered statistically significant.

\begin{tabular}{|c|c|c|c|c|c|c|}
\hline \multirow{2}{*}{$\begin{array}{l}\text { Age in } \\
\text { years }\end{array}$} & \multicolumn{2}{|c|}{ Group A } & \multicolumn{2}{|c|}{ Group B } & \multirow{2}{*}{$x^{2}$} & \multirow[b]{2}{*}{$\mathrm{p}$} \\
\hline & Count & Percent & Count & Percent & & \\
\hline $21-30$ & 225 & 59.2 & 215 & 56.6 & \multirow{4}{*}{0.69} & \multirow{4}{*}{0.709} \\
\hline $31-40$ & 141 & 37.1 & 148 & 38.9 & & \\
\hline $41-50$ & 14 & 3.7 & 17 & 4.5 & & \\
\hline Mean $\pm \mathrm{SD}$ & \multicolumn{2}{|c|}{$30.7 \pm 5$} & \multicolumn{2}{|c|}{$30.3 \pm 5.3$} & & \\
\hline
\end{tabular}

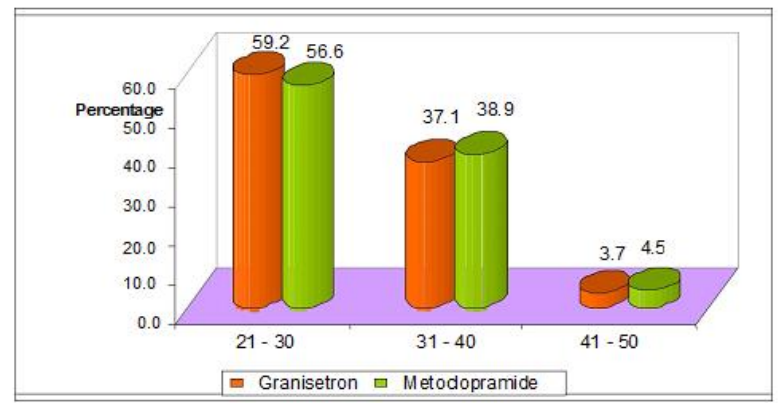

Average age in years were 30.7 and 30.3 respectively for patients selected for Group A and Group B. The Chi square test ( $p>0.05)$ shows that there is no statistical difference in age between the two groups. 
Table 2 Comparison of Sex based on Group

\begin{tabular}{|l|c|c|c|c|l|l|}
\hline \multirow{2}{*}{ Sex } & \multicolumn{2}{|l|}{ Group A } & \multicolumn{2}{|l|}{ Group B } & \multirow{2}{*}{$\mathrm{X}^{2}$} & $\mathrm{p}$ \\
\cline { 2 - 5 } & Count & Percent & Count & Percent & & \\
\hline \multirow{2}{*}{ Male } & 197 & 51.8 & 198 & 52.1 & 0.01 & \multirow{2}{*}{0.942} \\
\hline Female & 183 & 48.2 & 182 & 47.9 & & \\
\hline
\end{tabular}

Figure 2 Comparison of Sex based on Group

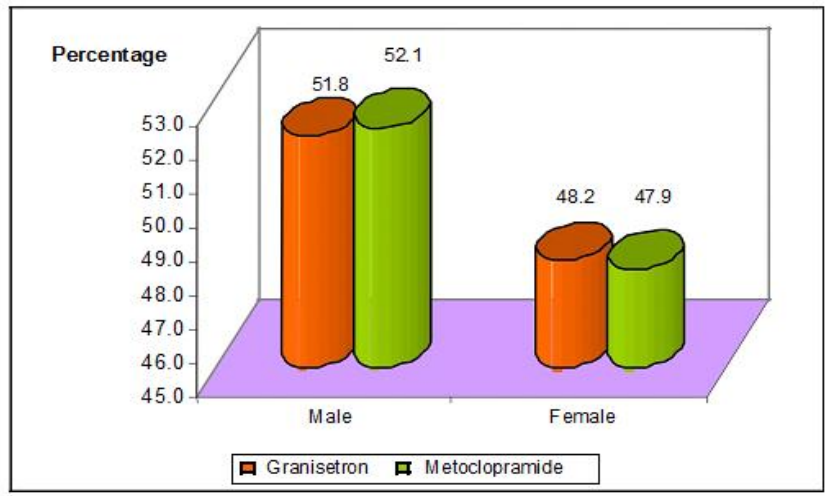

Among 380 cases of Group A 197 were males and 183 were females and among 380 cases of Group B 198 were males and 182 were females. The Chi square test $(\mathrm{p}>0.05)$ shows that there is no statistical difference in sex between the two groups.

\begin{tabular}{|l|l|l|l|l|l|l|}
\multicolumn{2}{|l}{ Table 3 Comparison of Weight based on Group } & \multirow{2}{*}{$\mathrm{X}^{2}$} & $\mathrm{p}$ \\
\hline \multirow{2}{*}{ Weight in kg } & \multicolumn{3}{|l|}{ Group A } & \multicolumn{2}{|l|}{ Group B } & \\
\cline { 2 - 5 } & Count & Percent & Count & Percent & & \\
\hline $41-50$ & 31 & 8.2 & 47 & 12.4 & & \\
\hline $51-60$ & 163 & 42.9 & 172 & 45.3 & & 0.14 \\
\hline $61-70$ & 168 & 44.2 & 145 & 38.2 & 5.33 & 9 \\
\hline $71-80$ & 18 & 4.7 & 16 & 4.2 & & \\
\hline Mean \pm SD & $61.3 \pm 6.6$ & $60.1 \pm 6.7$ & & \\
\hline
\end{tabular}

Figure 3 Comparison of Weight based on Group

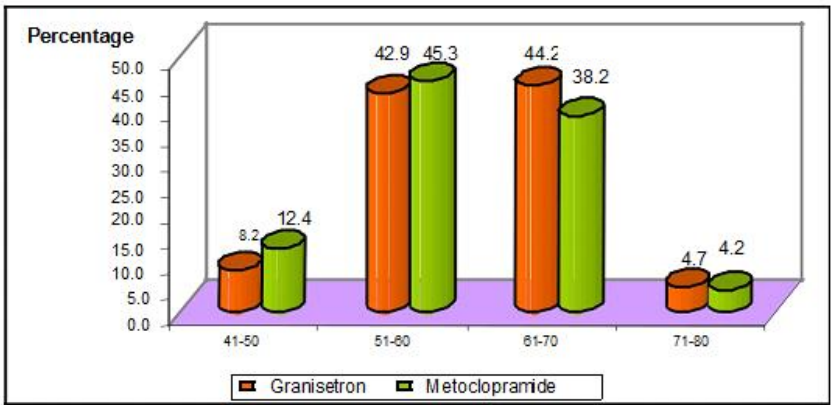

Average weight in $\mathrm{kg}$ were 61.3 and 60.1 respectively for patients selected for Group A and Group B . The Chi square test ( $p>0.05)$ shows that there is no statistical difference in weight between the two groups.

\begin{tabular}{|c|c|c|c|c|c|c|}
\hline \multirow{2}{*}{ ASA } & \multicolumn{2}{|c|}{ Granisetron } & \multicolumn{2}{|c|}{ Metoclopramide } & \multirow{2}{*}{$x^{2}$} & \multirow{2}{*}{$\mathrm{p}$} \\
\hline & Count & Percent & Count & Percent & & \\
\hline Grade 1 & 341 & 89.7 & 336 & 88.4 & 0.3 & \\
\hline Grade 2 & 39 & 10.3 & 44 & 11.6 & 4 & \\
\hline
\end{tabular}

Figure 4 Comparison of ASA(PS) status based on Group

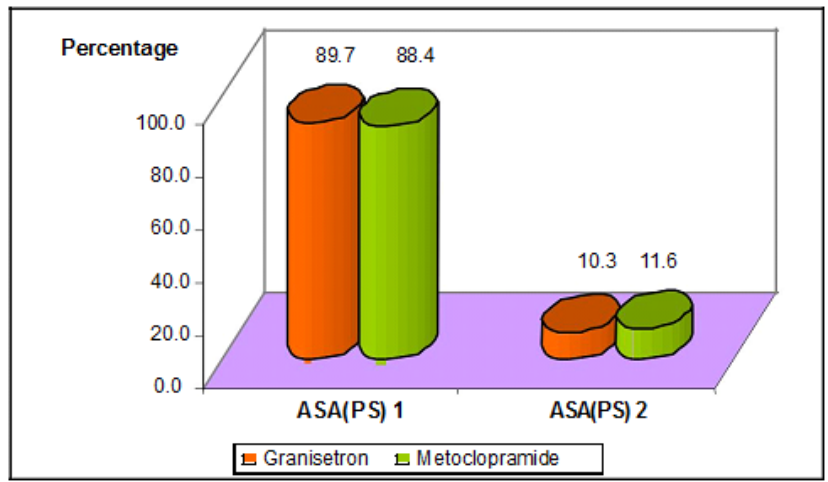

Among 380 cases of Group A 341(89.7\%) were ASA (PS) 1 and 39 (10.3\%) were ASA (PS) 2 and among 380 cases of Group B 336 were ASA(PS) 1 and 44 were ASA (PS) 2. The Chi square test ( $p>0.05)$ shows that there is no statistical difference in ASA (PS) between the two groups. Table 5 Comparison of Presence of Pain based on Group

Table 5 Comparison of Presence of Pain based on Group

\begin{tabular}{|l|l|l|l|l|l|l|}
\hline \multirow{2}{*}{ Pain } & \multicolumn{3}{|l|}{ Group A } & \multicolumn{2}{|l|}{ Group B } & \multirow{2}{*}{$\mathcal{X}^{2}$} \\
\cline { 2 - 5 } & Count & Percent & Count & Percent & & \\
No & 315 & 82.9 & 229 & 60.3 & \multirow{2}{*}{$47.84^{* *}$} & 0.000 \\
\hline Yes & 65 & 17.1 & 151 & 39.7 & & \\
\hline
\end{tabular}

**: - Significant at 0.01 level

Figure 5 Comparison of Presence of Pain based on Group

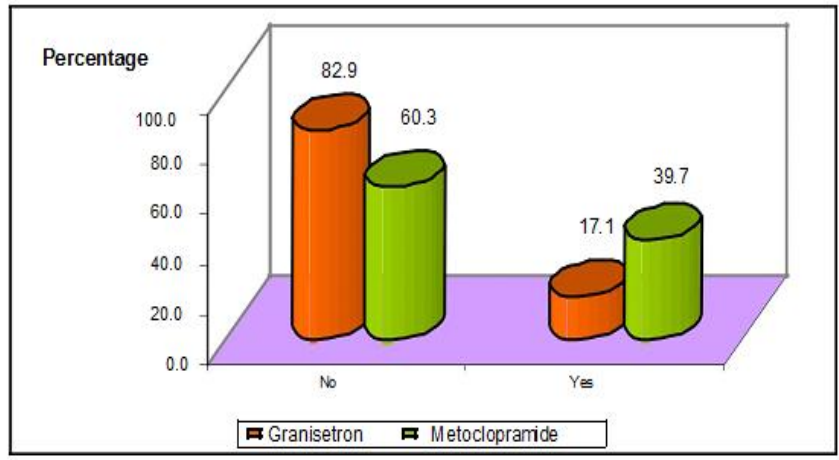

Among 380 cases of Group A 315 (82.9\%) had no pain (VRS 0) but 65 (17.1\%) complained of pain (VRS 1,2,3) and among 380 cases of Group B 229 $(60.3 \%)$ had no pain (VRS 0) but 151 (39.7\%) 
complained of pain (VRS 1,2,3). The Chi square test $(p<0.05)$ shows that there is statistical difference in presence of pain between the two groups.

Table 6 Comparison of Severity of Pain based on Group

\begin{tabular}{|c|c|c|c|c|c|c|}
\hline \multirow{2}{*}{ Pain } & \multicolumn{2}{|c|}{ Granisetron } & \multicolumn{2}{|c|}{ Metoclopramide } & \multirow{2}{*}{$x^{2}$} & \multirow{2}{*}{$\mathrm{p}$} \\
\hline & Count & Percent & Count & Percent & & \\
\hline No pain & 315 & 82.9 & 229 & 60.3 & \multirow{4}{*}{$47.83^{* *}$} & \multirow{4}{*}{0.000} \\
\hline Mild pain & 31 & 8.2 & 76 & 20.0 & & \\
\hline $\begin{array}{l}\text { Moderate } \\
\text { pain }\end{array}$ & 20 & 5.3 & 57 & 15.0 & & \\
\hline Severe pain & 14 & 3.7 & 18 & 4.7 & & \\
\hline
\end{tabular}

Figure 6 Comparison of Severity of Pain based on Group

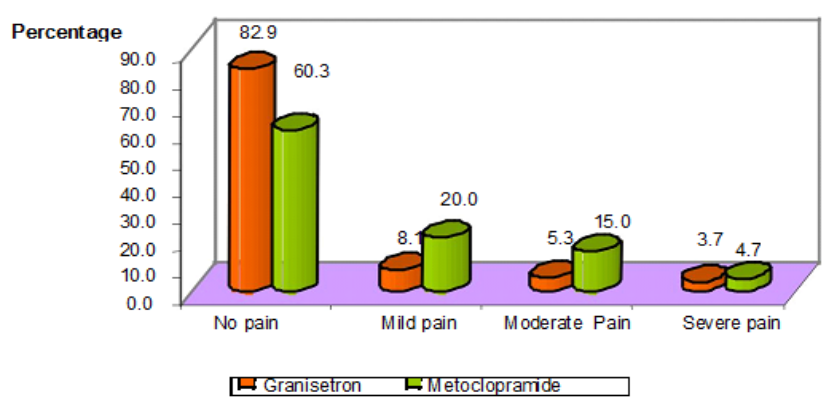

Among 65 cases which complained of pain in Group A, 31 patients had Mild pain VRS 1 (8.1\%), 20 had Moderate pain VRS 2 (5.3\%), 14 had Severe pain VRS 3 (3.7\%) but among 151 cases which complained of pain in Group B, 76 had Mild pain VRS 1 (20\%), 57 had Moderate pain VRS $2(15 \%), 18$ had Severe pain VRS 3 $(4.7 \%)$. The Chi square test $(\mathrm{p}<0.05)$ shows that there is statistical difference in severity of pain between the two groups.

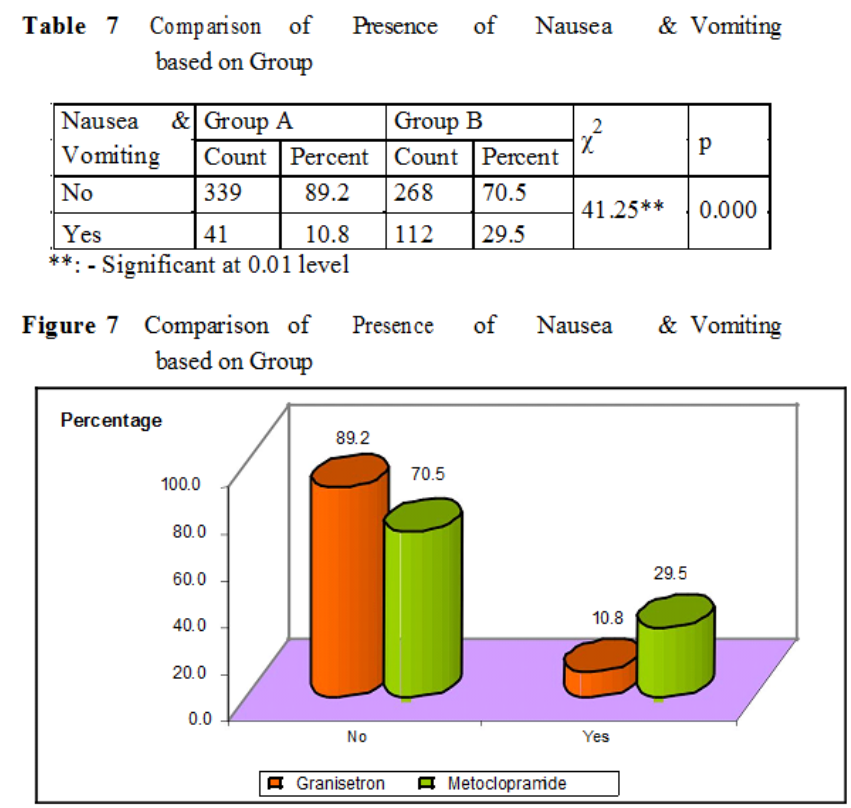

Among 380 cases in Group A, 41 patients (10.8\%) had nausea/vomiting but in Group Bं which had 380 patients, 112 patients $(29.5 \%)$ complained of nausea/vomiting. The Chi square test $(\mathrm{p}<0.05)$ shows that there is statistical difference in presence of nausea/vomiting between the two groups.

$$
\begin{aligned}
& \text { Table } 8 \text { Comparison of Severity of Nausea \& Vomiting } \\
& \text { based on Group }
\end{aligned}
$$

\begin{tabular}{|l|c|c|c|c|c|c|}
\hline \multirow{2}{*}{$\begin{array}{l}\text { Nausea } \\
\text { Vomiting }\end{array}$} & \multicolumn{2}{|c|}{ Group A } & \multicolumn{2}{|c|}{ Group B } & \multirow{2}{*}{ Z\# } & \\
\cline { 2 - 5 } & Count & Percent & Count & Percent & & \\
\hline Nil & 339 & 89.2 & 268 & 70.5 & & \\
\hline 1 & 38 & 10.0 & 76 & 20.0 & \multirow{2}{*}{$6.66^{* * *}$} & 0.000 \\
\hline 2 & 2 & 0.5 & 19 & 5.0 & & \\
\hline 3 & 1 & 0.3 & 17 & 4.5 & & \\
\# Mann-Whitney U Test $* *:-$ Significant at 0.01 level
\end{tabular}

Figure 8 Comparison of Severity of Nausea \& Vomiting based on Group

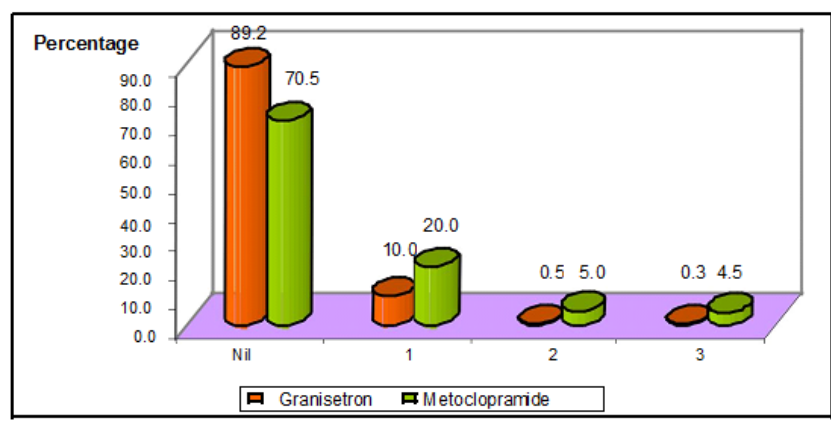

Among 41 patients of Group A which complained of Nausea/Vomiting, 38 had VAS (Visual analog score) score 1, 2 had VAS score 2, 1 had VAS score 1 but among 112 patients of Group B, 76 had VAS score 1, 19 had VAS score 2, 17 had VAS score 3 . The Mann Whitney U test $(\mathrm{p}<0.05)$ shows that there is statistical difference in severity of nausea/vomiting between the two groups.

\section{Discussion}

Nowadays anaesthesiologists are expected to provide their services with safe, uncomplicated accepted technique of anaesthesia to patient.

The incidence and severity of pain on injection may be more when intravenous cannulation is performed in small veins. Hypertonic drugs, size of needle, site of injection, speed of injection and many other factors are important to produce pain on injection. 
Again pain on injection is considerably more at extremes of age. In paediatric patients many times un cooperation may result in multiple pricks and more incidence of pain. In geriatric patients overall pain threshold is decreased giving rise to more incidence of pain.

Propofol (2,6, di isopropyl phenol) was introduced in practice of anaesthesia as an induction agent in early 1970's. It gained popularity due to its rapid induction and rapid recovery .

Overall pain on injection of propofol ranges from 25 to $100 \%$ at vein on dorsum of hand (Stark R.D. et al $1986^{[41]}$, Scott R.P.F.et al $1988^{[16]}$, Johnson R.A. et al $1999^{[19]}$ ) and 3 to $26 \%$ only when injected into proximal veins.

Gehan et al $1991^{[81]}$ quoted that pain on injection of propofol was attributed to the stabilizing agent Cremophor EL but persisted even though replaced by soybean oil (Brooker J et al $1985^{[82]}$ and McCulloch M.J. et al $1985^{[7]}$ ).

To overcome this pain on injection, McCulloch M.J. et al $1985^{[7]}$ suggested injection in large veins. Hiller S.C. et al $1996{ }^{[85]}$ suggested decreasing speed of injection, dilution in 5\% dextrose or $10 \%$ intralipid or pretreatment with narcotics or thiopentone before propofol administration.

However, pain on injection of propofol, which has been reported to occur in $28 \%-90 \%$ of patients, is a major drawback to its use. Various methods of minimizing pain on injection have been proposed. Based on proposed mechanisms and factors associated with propofol injection pain, several methods for prevention of pain have been tried with varying degrees of success.

Propofol belong to group of phenol that can irritate the skin, mucous membrane, and venous intema $\left({ }^{[8]}\right.$ Ambesh SP et al 1999). Scott etal ${ }^{[54]}$ speculated that the injection pain is caused by activation of the kallikrein-kinin system either by propofol or the lipid solvent, there by generating kinins, probably bradykinin. Bradykinin, by producing local vasodilation and hyper permeability, may increase the contact between the aqueous phase propofol and the free nerve ending resulting in pain on injection $\left({ }^{[83]}\right.$ Coderre TJ et al 1993). This pain has a 10-20s delayed onset. But immediate pain may be caused by direct irritation of afferent nerve endings in the veins.

The use of pretreatment to reduce the pain of injection of propofol has become a standard practice. The pain of injection at the induction of anaesthesia can cause agitation and hinder the smooth induction of anaesthesia and thus an effective method of prevention would be beneficial.

This study attempts to compare the effectiveness of Granisetron and Metoclopramide on reducing propfol injection pain. Granisetron and Metoclopramide are used commonly as antiemetic drugs.

In the present study, I evaluated the statistical difference in age, sex, weight, ASA(PS) among the two groups. There was no statistical difference in these. This result was similar to study conducted by Ahmed etal ${ }^{[71]}$ 2012. They also did not get any statistical difference in age, weight, ASA physical status.

Average age in years for group A and group B were 30.7 and 30.3 respectively. In 21-30 year old age, group A has 225 (59.2\%), group B has 215 (56.6\%) while in 31-40 year old age, group A has $141(37.1 \%)$, group B has 148 (38.9\%) while in 41-50 year old age, group A has 14 (3.7\%), group B has $17(4.5 \%)$. The $\mathrm{p}$ value was 0.709 . The Chi square test $(p>0.05)$ shows that there is no statistical difference in age between the two groups.

Among 380 cases of Group A 197 (51.8\%) were males and $183(48.2 \%)$ were females and among 380 cases of Group B 198 (52.1\%) were males and $182(47.9 \%)$ were females. Males are predominant in my study. The $\mathrm{p}$ value was 0.942 . The Chi square test $(p>0.05)$ shows that there is no statistical difference in sex between the two groups.

Average weight for group A and group B were $61.3 \mathrm{~kg}$ and $60.1 \mathrm{~kg}$ respectively. In group A 31 (8.2\%) patients had weight between $41-50 \mathrm{~kg}$ while in group B it was 47 (12.4\%). In Group A $163(42.9 \%)$ had weight between $51-60 \mathrm{~kg}$ while in 
Group B it was 172(45.3\%). In group A 168 (44.2\%) had weight between $61-70 \mathrm{~kg}$ while in Group B it was 145 (38.2\%). In Group A 18 (4.7\%) patients had weight between $71-80 \mathrm{~kg}$ while in Group B it was $16(4.2 \%)$. The $p$ value was 0.149 . The Chi square test $(p>0.05)$ shows that there is no statistical difference in weight between the two groups.

Among 380 cases of Group A 341 (89.7\%) were ASA(PS) 1 and 39 (10.3\%) were ASA(PS) 2 and among 380 cases of Group B 336 (88.4\%) were ASA(PS) 1 and 44 (11.6\%) were ASA(PS) 2. The $\mathrm{p}$ value was 0.561 . The Chi square test $(\mathrm{p}>0.05)$ shows that there is no statistical difference in ASA(PS) between the two groups.

In my study, the test drugs were given as pretreatment in $2 \mathrm{ml}$ solution over 5 seconds followed by venous occlusion of arm for 1 minute. This was similar to the way the study conducted by to R.A.

Johnson et al $1990^{[19]}$, S.P. Ambesh et al $1999^{[8]}$, Ahmed etal ${ }^{[71]}$.

According to Hiller S.C.et al $1992^{[59]}$ speed of injection directly correlates with pain on injection that is why speed of test drug and propofol were kept constant as 4 seconds.

No premedication was given to patients except ranitidine because it might interfere with perception of pain of propofol injection . Best way of measuring pain in the clinical setting is by verbal response or its derivatives, the visual analogue scale (VAS) (Ohnhaus EE et al 1975 ${ }^{[84]}$ ). The VAS appears to be more sensitive than the categorical scales at measuring smaller changes. A four- point verbal categorical scoring system (VRS) was chosen in this study rather than VAS as it was very simple to use by the patient and as appropriate hand eye coordination required for a VAS might not be present in all patients during the rapidly changing state of consciousness of anaesthesia induction.

Group A patients pretreated with Granisetron has less incidence of pain than in group B patients which were pretreated with Metoclopramide. Among 380 cases of Group A 315 patients
(82.9\%) had no pain (VRS 0) but 65 patients (17.1\%) complained of pain (VRS 1,2,3) and among 380 cases of Group B 229 patients $(60.3 \%)$ had no pain (VRS 0) but 151 patients (39.7\%) complained of pain (VRS 1,2,3). The p value was 0.000 . The Chi square test $(\mathrm{p}<0.05)$ shows that there is statistical difference in presence of pain between the two groups.

In the study by Ahmed etal 2012 $2^{[71]}, 15 \%$ complained of pain when Granisetron given as pretreatment before propofol injection. In the study by Liaw WJ etal $1999^{[11]}, 23 \%$ complained of pain when metoclpramide was given as preatreatment before propofol injection.

Group A patients pretreated with Granisetron has less severity of pain than in group B patients which were pretreated with Metoclopramide. Among 65 cases with complaints of pain in Group A, 31 patients (8.1\%) had mild pain (VRS 1), 20 (5.3\%) had moderate pain (VRS 2), 14 (3.7\%) had severe pain (VRS 3) but among 151 cases which complained of pain in Group B, 76 (20\%) had mild pain (VRS 1), 57 (15\%) had moderate pain (VRS 2), 18 (4.7\%) had severe pain (VRS 3). The $\mathrm{p}$ value was 0.000 . The Chi square test $(\mathrm{p}<0.05)$ shows that there is statistical difference between the two groups.

Ye $\mathrm{Jh}$ et $a l^{[37]}$ suggested the dual mechanism of action of ondansetron as a sodium channel blocker and 5HT3 receptor antagonist (peripheral 5HT3 receptors involve nociceptive pathways). The exact mechanism of alleviation of propofol injection pain by Granisetron is not known. This may have been the result of a peripheral local anesthetic action, which attenuated the afferent pain pathway rather than a central analgesic effect, similar to the mechanism of ondansetron (i.e., blockage of sodium channel and antagonism of 5HT3 receptor).

Among 380 patients in group A, 339 patients had no nausea/vomiting (89.2\%) but 41 patients $(10.8 \%)$ had nausea/vomiting while in group $\mathrm{B}$, 268 patients $(70.5 \%)$ had no nausea/vomiting but 112 patients $(29.5 \%)$ complained of nausea/ vomiting. The $\mathrm{p}$ value is 0.000 . The Chi square 
test $(p<0.05)$ shows that there is statistical difference between the two groups. Thus Granisetron has less incidence of nausea/vomiting than Metoclopramide.

Among 41(10.8\%) patients of group A which complained of nausea/vomiting, 38 (10\%) had VAS score 1, 2 (0.5\%) had VAS score 2, $1(0.3 \%)$ had VAS score 1 but among 112 patients $(29.5 \%)$ of Group B, 76 (20\%) had VAS score 1, 19 (5\%) had VAS score 2, $17(4.5 \%)$ had VAS score 3 . The $\mathrm{p}$ value is 0.000 . The Mann Whitney $U$ test $(p<0.05)$ shows that there is statistical difference between the two groups. Thus Granisetron has less severity of nausea/vomiting than Metoclopramide. A Wadaskar etal ${ }^{[86]}$ The incidence of nausea and vomiting over a period of 24 hour were found in $20 \%$ of patients who had received Granisetron, $45 \%$ of patients who had received ondansetron and $77.5 \%$ of patients who had received placebo. Granisetron is more effective than ondansetron and placebo in controlling postoperative nausea $\&$ vomiting after laparoscopic gynecological surgery. Sabina Yeasmeen etal 2006 Intravenous Granisetron,

Ondansetron and Metoclopramide in the Prevention and Treatment of Post Operative Nausea and Vomiting after Laparoscopic Cholecystectomy - A Comparative Study.The incidence of emesis free(no nausea) was significantly higher in patients who received Ganisetron $(90.0 \%, 27 / 30)$ than in those who received Ondansetron $[(66.7 \%, 20 / 30), \mathrm{p}=0.028]$ or Metoclopramide [(40.0\%, 12/30), $\mathrm{p}=0.000]$. The incidenceof vomiting free (no vomiting) was significantly higher in patients who received Granisetron $(93.3 \%, 28 / 30)$ than inthose who received Ondansetron [73.3\%, 22/30), $\mathrm{p}=0.037]$ or Metoclopramide [46.7\%, 14/30), $\mathrm{p}=0.000]$. Granisetron was associated with greater patients' satisfaction than Ondansetron and Metoclopramide $40 \%, 20 \%$ and $10 \%$ of patients respectively. No need for another rescue antiemetic medication was achieved in $86.7 \%$ of patients with Granisetron, $70.60 \%$ with Ondansetron and 53.3\% with Metoclorpramide.
My study had few limitations. Occlusion at mid forearm was done manually, which will vary from person to person, this could have been overcome by using tourniquet with constant pressure. Also drug could have been injected using syringe pump instead of injecting manually.

The incidence of adverse reaction were negligible in my study may be attributed to selection of patients of ASA grade I and II only.

\section{Summary}

760 patients selected for study have no statistical difference in age, sex, weight and ASA(PS) status. 380 of them were given Granisetron (group A) and 380 were given Metoclopramide (group B) before Propofol injection. 65 patients (17.1\%) complained of pain in group A that is 31 patients (8.1\%) with mild pain (VRS 1), 20 patients (5.3\%) with moderate pain (VRS 2), 14 patients $(3.7 \%)$ with severe pain (VRS 3) . 151 patients (39.7\%) complained of pain in group B that is 76 patients (20\%) with mild Pain (VRS 1), 57 patients (15\%) with moderate pain (VRS 2), 18 patients (4.7\%) with severe pain (VRS 3). The Chi square test $\mathrm{P}<$ 0.05 shows that Granisetron is superior to Metoclopramide in reducing propofol injection pain.

In group A 41 patients (10.8\%) complained of post operative nausea/vomiting that is $38(10 \%)$ had VAS score $1,2(0.5 \%)$ had VAS score $2,1(0.3 \%)$ had VAS score 1. In group B 112 patients (29.5\%) complained of post operative nausea /vomiting that is $76(20 \%)$ had VAS score 1, 19 (5\%) had VAS score 2, $17(4.5 \%)$ had VAS score 3 .The Mann Whitney $U$ test $\mathrm{P}<0.05$ shows that Granisetron is superior to Metoclopramide in reducing post operative nausea/ vomiting.

\section{Conclusion}

Intravenous Granisetron at a dose of $2 \mathrm{mg}$ was more effective than intravenous Metoclopramide at a dose of $10 \mathrm{mg}$ along with manual occlusion for one minute in reducing Propofol injection pain when given before Propofol injection. Also, Granisetron was more effective than Metoclopr- 
amide in reducing post operative nausea and vomiting . No significant adverse effects were noted with either drugs.

\section{Bibliography}

1. Smith I, White PF, Nathanson M, Gouldson R. Propofol: An update on its clinical use. Anesthesiology 1994;81:1005-43.

2. Macario A, Weinger M, Truong P, Lee M. Which clinical anesthesia outcomes are both common and important to avoid? The perspective of a panel of expert anesthesiaologists. Anesth Analg 1999;88:1085-91.

3. Hynynen M, Korttila K, Tammisto T. Pain on IV injection of propofol (ICI 35868) in emulsion formulation: Short communication. Acta Anaesthesiol Scand 1985;29: 651-2.

4. King SY, Davis FM, Wells JE, Murchinson DJ, Pryor PJ. Lidocaine for the prevention of pain due to injection of propofol. Anesth Analg 1992;74:246-9.

5. McCrirrick A, Hunter S. Pain on injection of propofol: The effect of injectate temperature. Anaesthesia 1990;45:443-4.

6. Stokes DN, Robson N, Hutton P. Effect of diluting propofol on the incidence Of pain on injection and venous sequelae. $\mathrm{Br} \mathrm{J}$ Anaesth 1989; 62:202-3.

7. McCulloch MJ, Lees NW. Assessment and modification of pain on injection with propofol (Diprivan). Anaesthesia 1985; 40:1117-20.

8. Ambesh SP, Dubey PK, Sinha PK. Ondansetron pretreatment to alleviate pain on propofol injection: A randomized, controlled, double-blind study. Anesth Analg 1999;89:197-9.

9. Tan $\mathrm{CH}$, Onsiong MK, Kua SW. The effect of ketamine pretreatment on propofol injection pain in 100 women. Anaesthesia1998;53:296-304.

10. Agarwal A, Ansari MF, Gupta D, Pandey R, Raza M, Singh PK, et al. Pretreatment with thiopental for prevention of pain associated with propofol injection. Anesth Analg 2004;98:683-6.

11. Liaw WJ, Pang WW, Chang DP, Hwang MH. Pain on injection of propofol: The mitigating influence of metoclopramide using different techniques. Acta Anaesthesiol Scand 1999;43:24-7.

12. Fletcher JE, Seavell CR, Bowen DJ. Pretreatment with alfentanil reduces pain caused by propofol. $\mathrm{Br} \mathrm{J}$ Anaesth 1994;72:342-4.

13. Liljeroth E, Karlsson A, Lagerkranser M, Akeson J. Low dose propofol reduces the incidence of moderate to severe local pain induced by the main dose. Acta Anaesthesiol Scand 2007;51:460-3.

14. Mangar D, Holak EJ. Tourniquet at 50 $\mathrm{mmHg}$ followed by intravenous lidocaine diminishes hand pain associated with propofol injection. Anaesth Analg 1992;74:250-15.

15. Valtonen M, Lisalo E, Kanto J, Rosenberg P. Propofol as an induction agentin children: Pain on injection and pharmacyokinetics. Acta Anaesthesiol Scand 1989;33:152-5.

16. Scott RP, Sunders DA, Norman J. Propofol: Clinical strategies for preventing the pain on injection. Anaesthesia 1988;43 :492-4.

17. Mattila MA, Koski EM. Venous sequelae after intravenous propofol: A comparison with methohexitone in short anaesthesia. Postgrad Med J 1985;61:162-4.

18. King SY, Davis FM, Wells JE. Lidocaine for the prevention of pain due to injection of propofol. Anesth Analg 1992;74:246-9.

19. Johnson RA, Harper NJ, Chadwick S, Vohra A. Pain of injection of propofol: Methods of alleviation. Anaesthesia 1990;45:439-42.

20. McCrirrick A, Hunter S. Pain on injection of propofol: The effect of injectate temperature. Anaesthesia 1990;45:443-4. 
21. Barker P, Langton JA, Murphy $P$, Rowbotham DJ. Effect of prior administration of cold saline on pain during propofol injection: A comparison with cold propofol and propofol with lignocaine. Anaesthesia 1991;46:1069-70.

22. Klement W, Arndt JO. Pain on injection of propofol: Effects of concentration and diluent. Br J Anaesth 1991;67:281-4.

23. Dolin SJ, Cashman JN, Bland JM: Effectiveness of acute postoperative pain management: I. Evidence from published data. Br J naesth 2002; 89:409-423.

24. Palazzo M, Evans R: Logistic regression analysis of fixed patient factors For postoperative sickness: A model for risk assessment. Br J Anaesth 1993; 70:135140.

25. Cohen MM, Duncan PG, DeBoer DP, Tweed WA: The postoperative interview: Assessing risk factors for nausea and vomiting. Anesth Analg 1994; 78:7-16.

26. Koivuranta M, Laara E, Snare L, Alahuhta S: A survey of postoperativenausea and vomiting. Anaesthesia 1997; 52:443-449.

27. Apfel CC, Laara E, Koivuranta M, et al: A simplified risk score for predicting postoperative nausea and vomiting: Conclusions from cross-validations between two centers. Anesthesiology1999; 91:693-700.

28. Eberhart LHJ, Hogel J, Seeling W, et al: Evaluation of three risk scores to predict postoperative nausea and vomiting. ActaAnaesthesiol Scand 2000; 44:480-488.

29. Visser K, Hassink EA, Bonsel GJ, et al: Randomized controlled trial of total intravenous anesthesia with propofol versus inhalation anesthesia with isoflurane-nitrous oxide: Postoperative nausea with vomiting and economic analysis. Anesthesiology 2001; 95:616-626.

30. Stadler M, Bardiau F, Seidel L, et al: Difference in risk factors for postoperative nausea and vomiting. Anesthesiology 2003; 98:46-52.
31. Watcha MF, White PF: Postoperative nausea and vomiting: Its etiology, treatment, and prevention. Anesthesiology 1992; 77:162-184.

32. Macario A, Weinger M, Carney S, Kim A: Which clinical anesthesia outcomes are important to avoid? The perspective of patients. Anesth Analg 1999; 89:652-658

33. Darkow T, Gora-Harper ML, Goulson DT, Record KE: Impact of antiemetic selection on postoperative nausea and vomiting and patient satisfaction. Pharmacotherapy 2001; 21:540-548.

34. Bremner WG, Kumar CM: Delayed surgical emphysema, pneumomediastinum and bilateral pneumothoraxes after postoperative vomiting. $\mathrm{Br} J$ Anaesth 1993; 71:296-297.

35. Schumann R, Polaner DM: Massive subcutaneous emphysema and sudden airway compromise after postoperative vomiting. Anesth Analg 1999; 89:796-797.

36. Gold BS, Kitz DS, Kecky JH, Neuhaus JM: Unanticipated admission to the hospital following ambulatory surgery. JAMA 1989; 262:3008-301

37. Ye JH, Mui WC, Ren J, Hunt TE, Wu WH, Zbuzek VK. Ondansetron exhibits the properties of a local anesthetic. Anesth Analg 1997;85:1116-21.

38. Desmond PV, Watson KJ. Metoclopromide- a review. Med J Aus1986; 144:366-9

39. Albibi R, McCallum RW. Metoclopromide-Pharmacology and clinical application. Ann Int Med 1983;93:86-95.

40. Mecklem DW. Propofol injection pain: Comparing the addition of lignocaine or metoclopramide. Anaesth Intensive Care 1994;22:568-70.

41. Stark RD, Binks SM, Dutka VN, O'Connor KM, Arnstein MJ, Glen JB.: A review of the safety and tolerance of propofol ('Diprivan'):Postgraduate Medical Journal 1985;61 Suppl 3:152-6. 
42. Nightingale $P$, Healy E, Hargreaves J, McGuiness K, Kay B. Propofol in emulsion form: induction characteristics and venous sequelae. Eur $J$ Anaesthesiol 1985; 2 : 361-8.

43. Marcario A, Weinger M, Truong P, Lee M. Which clinical anesthesiaoutcomes are both common amd important to avoid? The perspective of a panel of expert anesthesiologists. AnesthAnalg 1999; 88: 1085-91.

44. Tan CH, Onsiong M. Pain on injection of propofol. Anaesthesia 1998; 53: 468-76.

45. Eriksson M, Englesson S, Niklasson F, Hartvig P. Effect of lignocaine and $\mathrm{pH}$ on propofol-induced pain. Br J Anaesth 1997; 78: 502-6.

46. Doenicke A, Roizen M, Rau J, Kellerman W, Babl J. Reducing pain during propofol injection: The role of the solvent. AnesthAnalg 1996; 82: 472-4.

47. Doenicke A, Roizen M, Rau J et al. Pharmacokinetics and pharmacodynamics of propofol in a new solvent. Anesth Analg 1997; 85: 1399-1403

48. Nishiyama T. How to decrease pain at rapid injection of propofol: effectiveness of flurbiprofen. J Anesth 2005; 19: 273-6.

49. Ohmizo H, Obara S, Iwama H. Mechanism of injection pain with long- and longmedium chain triglyceride emulsive propofol. Can J Anaesth 2005; 52: 595-9.

50. Ando R, Watanabe C. Characteristics of propofol-evoked vascular pain in anaesthetized rats. Br J Anaesth 2005; 95: 384-92.

51. Song D, Hamza M, White P, Byerly S, Jones S, Macaluso A. Comparison of a lower-lipid propofol emulsion with the standard emulsion for sedation during monitored anesthesia care. Anesthesiology 2004; 100: 1072-5.

52. Sosis MB, Braverman B. Grouth of staphylolcoccus aureus in four intravenous anesthetics. Anesth Analg 1993; 77: 766-8.

53. Sosis M, Braverman B, Villaflor E. Propofol but not thiopental supports the growth of candida albicans. Anesth Analg $1995 ; 81: 132-4$.

54. Ozer Z, Ozturk C, Altukan A, Cinel I, Oral $\mathrm{U}$. Inhibition of bacterial growth by lignocaine in propofol emulsion. Anaesthesia Intensive Care 2002; 30: 179-82.

55. Dubey P, Kumar A. Pain on injection of lipid-free propofol and propofol emulsion containing medium-chain triglyceride; A comperative study. Anesth Analg 2005; 101: 1060-2.

56. Fechner J, Ihmsen H, Hatterscheid D et al. Pharmacokinetics and clinical pharmacodynamics of the new propofol prodrug GPI 15715 in volunteers. Anesthesiology 2003; 99: 303-13.

57. McCrirrick A, Hunter S. Pain on injection of propofol: the effect of injectate temperature. Anaesthesia 2005; 45: 1090-1.

58. Yamakage M, Iwasaki S, Satoh J-I, Namiki A. Changes in concentration of free propofol by modification of the solution.Anesth Analg 2005; 101: 385-8.

59. Picard P, Tramér M. Prevention on injection with propofol: A quantitative systematic review. Anesth Analg 2000; 90: 963-9.

60. Klement W, Arndt JO. Pain on injection of propofol. Effects of concentration and diluent. Br J Anaesth 1991; 67: 281-4.

61. Huang CL, Wang Y, Cheng YJ, Susetio L, Liu CC. The effect of carrier intravenous fluid speed on the injection pain of propofol. Anesth Analg 1995;81: 1087-8.

62. Huang YW, Buerkle $\mathrm{H}$, Lee $\mathrm{TH}$ et al. Effect of pretreatment with ketorolac on propofol injection pain. Acta Anaesthesiol Scand2002; 46: 1021-4.

63. Angst M, MS , Zupfer H, Tatanu C, BrockUtne J. Reduction of propofol injection pain with a double lumen iv set. J Clin Anesth 1997; 9: 462-6.

64. McDonald DS, Jameson P. Injection pain with propofol: Reduction with aspiration of blood. Anaesthesia 1996; 51: 878-80. 
65. Davies AF, Vadodaria B, Hopwood B, Dexter T, Conn D. Efficacy of microfiltration in decreasing propofolinduced pain.Anaesthesia 2002; 57: 557-61

66. Hellier C, Newell S, Barry J, Brimacombe J. A 5-microm filter does not reduce propofol-induced pain. Anaesthesia 2003; 58: 802-3.

67. Finkelstein A, Lokhandwala B, Pandey NS. Particulate contamination of an intact glass ampoule. Anesthesiology 1990;362-3.

68. Lomax D. Propofol injection pain. Anaesth Intensive Care 1994; 22: 500-1.

69. Seki S, Sekine R, Aketa K et al. Induction of anesthesia with propofol through a central venous catheter. Masui 1999; 48: 62-6

70. Shimizu T, Inomata S, Kihara S, Toyooka $\mathrm{H}$, Brimacombe JR. Rapid injection reduces pain on injection with propofol. Eur Jnaesthesiol 2005; 22: 394-6.

71. Ahmed A, Sengupta S, Das T, Rudra A, Iqbal A. Pre-treatment with intravenous Granisetron to alleviate pain on propofol injection: A double blind, randomised, controlled trial. Indian $\mathbf{J}$ Anaesth. 2012;56:135-8.

72. Dhananjay Kumar Singh, Parul indal, and Gaurav Singh Comparative study of attenuation of the pain caused by propofol intravenous injection, by Granisetron, magnesium sulfate and nitroglycerine Saudi J Anaesth. 2011 Jan-Mar; 5(1): 5054.

73. Dubey PK, Prasad SS. Pain on injection of propofol: the effect of Granisetron pretreatment. Clin J Pain. 2003 MarApr;19(2):121-4

74. Zahedi H, Maleki A, Rostami G. Ondansetron pretreatment reduces pain on injection of propofol. Acta Med Iran 2012;50:239-43.

75. Piper SN, Röhm KD, Papsdorf M, Maleck WH, Mattinger P, Boldt J. Dolasetron reduces pain on injection of propofol.
Anasthesiol Intensivmed Notfallmed

Schmerzther 2002;37:528-31.

76. Dipali Singh, SathyanarayanJagannath,

Shio Priye, Sivaprakash, Chandrashekar kadli, Durgaprasad Reddy Prevention of propofol injection pain: Comparison between lidocaine and ramosetronJ Anaesthesiol Clin Pharmacol. 2014 AprJun; 30(2): 213-216.

77. Reyhan Polat Meltem Aktay, Onur Özlü The effects of remifentanil, lidocaine metoclopramide, or ketamine pretreatment on propofol injection pain M.E.J. anesth 21 (5), 2012.

78. Fujii $\mathrm{Y}^{1}$, Uemura A. Effect of metoclopramide on pain on injection of propofol. Anaesth Intensive Care. 2004 Oct;32(5):653-6.

79. Ganta R, Fee JP. Pain on injection of propofol: comparison of lignocaine with metoclopramide. $\mathrm{Br} \mathrm{J}$ Anaesth. 1992 Sep;69(3):316-7.

80. Movafegh A, Mir Eskandari M, Eghtesadi Araghi P AComparison Of Metoclopramide And Lidocaine For Preventing Pain On Injection Of Propofol Tehran Univ Med J 2003, 61(4): 274-280.

81. Gehan G.et al, Optimal dose of Lignocaine for preventing pain on injection of Propofol; British Journal of Anaesthesia 1991; 66: 324-326

82. Brooker J. et al, Effect of Lignocaine on pain caused by Propofol injection; Anaesthesia; 1985.

83. Contribution of central neuroplasticity to pathological pain: review of clinical and experimental evidence.Coderre TJ, Katz J, Vaccarino AL, Melzack R.Pain. 1993 Mar; 52(3):259-85

84. Ohnhaus, E. E. \& Adler, R.(1975), Methodological problems in measurement of pain: A comparison between VAS \& VRS, Pain, 1,379-84.

85. Hiller A et al, Injection pain, cardiovascular changes and recovery 
following induction of anaesthesia with Propofol in combination with alfentanil or lidocaine in children; ActaAnaesthesia Scandinavia; 1992 Aug; 36(6): 564-8.

86. A Wadaskar, N Swarnkar, A Yadav. Granisetron has superior control over postoperative nausea and vomiting than ondansetron in gynecological surgeries: a placebo controlled double-blind clinical study. The Internet Journal of Anesthesiology. 2008 Vol 20 Number 1.

87. Sabina Yeasmeen, Rubina Yasmin, AKM Akhtaruzzaman, UH Shahera Khatun. Intravenous Granisetron, Ondansetron and Metoclopramide in the Prevention and Treatment of Post Operative Nausea and Vomiting after Laparoscopic Cholecystectomy - A Comparative Study. Journal of BSA, Vol. 19, No. 1 \& 2, 2006 p20-27. 